\title{
The annual direct costs of stable COPD in Greece
}

This article was published in the following Dove Press journal:

International Journal of COPD

\section{Eirini Stafyla' \\ Mary Geitona ${ }^{2}$ \\ Theodora Kerenidi' \\ Athina Economou ${ }^{3}$ \\ Zoe Daniil' \\ Konstantinos I \\ Gourgoulianis'}

'Respiratory Medicine Department, University of Thessaly School of Medicine, University Hospital of Larissa, Larissa, ${ }^{2}$ School of Social Sciences, University of Peloponnese, Corinth, ${ }^{3}$ Department of Economics, University of Thessaly, Volos, Greece

Correspondence: Eirini Stafyla Respiratory Medicine Department, University Hospital of Larissa, Mezourlo (Biopolis), 4III 10 Larissa, Greece

Tel +30 24I 3502896

$\mathrm{Fax}+3024 \mid 350 \quad 1563$

Email eirinistaf@hotmail.com
Introduction: Chronic obstructive pulmonary disease (COPD) places a major burden on health care systems and has substantial economic effects; however, the cost of stable disease in Greece has never been thoroughly explored. The objective of the study was to estimate the annual COPD patient cost during the maintenance phase and explore the relationships between the cost and disease severity.

Methods: Data were collected from 245 COPD patients (male: 231 , mean age: $69.5 \pm 8.8$ years) who visited the outpatient unit of University Hospital of Larissa in 2014 and 2015. Patients were classified according to Global Initiative for Chronic Obstructive Lung Disease (GOLD) guidelines, and the patients' direct cost during the maintenance phase was calculated.

Results: Eleven percent of COPD patients were stage I, 48.2\% were stage II, 29\% were stage III, and $11.8 \%$ were stage IV. According to the GOLD groups, $23.3 \%$ of patients were grade A, $15.5 \%$ were grade B, $22.9 \%$ were grade $\mathrm{C}$, and $38.4 \%$ were grade $\mathrm{D}$. The mean annual direct cost for stable disease was estimated at $€ 1,034.55$ per patient, of which $€ 222.94$ corresponded to out-of-pocket payments. The annual cost ranged from $€ 408.23$ to $€ 2,041.89$ depending on GOLD stages (I-IV) and from $€ 550.01$ to $€ 1,480.00$ depending on GOLD groups (A-D). The key cost driver was pharmaceutical treatment, which reflected almost $71 \%$ of the total expenses for the management of stable disease. The mean annual per-patient cost was two to three times higher for those with advanced disease (stages III-IV) compared to those with stages I-II disease, and it doubled for "high-risk" patients (groups C-D) compared to "low-risk" patients (groups A-B). Conclusion: The cost of COPD during the maintenance phase is remarkable, with the key cost driver found to be pharmaceutical treatment and social insurance funds the key payer for treating COPD patients in Greece. The cost of stable disease is proportional to the severity of COPD, and it is doubled in patients who belong to high-risk groups.

Keywords: stable COPD, direct cost, annual cost, GOLD stages, GOLD groups, Greece

\section{Introduction}

Chronic obstructive pulmonary disease (COPD) is a global health problem afflicting millions of people worldwide, as according to World Health Organization estimates 65 million people suffer from the disease. ${ }^{1}$ In 2010, the Global Burden of Disease Study ranked COPD as the third leading cause of mortality and the ninth leading cause of disability-adjusted life years lost. ${ }^{2-3}$ In Greece, the prevalence of COPD was found to range from $3.5 \%$ (in general population) to $8.4 \%$ (in those aged $>35$ years with smoking history) and $18.4 \%$ (in individuals $>30$ years old); ${ }^{4-6}$ however, there are many studies supporting the idea that the disease remains largely underestimated and undiagnosed. ${ }^{4,7-10}$

COPD places a major burden on health care systems, as given the prevalence of the disease and the duration of illness for those affected, medical expenditures for treating COPD and the indirect costs of morbidity can represent a substantial economic and social burden. ${ }^{11,12}$ In 2010, the economic burden of COPD in the United States was 
projected to be approximately US $\$ 49.9$ billion, ${ }^{13}$ while in Europe the cost of COPD was estimated to be $€ 48.4$ billion in 2011 , of which $€ 23.3$ billion was referred to direct health care expenditures. ${ }^{14}$ In Greece, there are very few studies using different methods - estimating the cost of COPD. A recent study reported a total annual per-patient cost of $€ 4,730,{ }^{15}$ while another study focusing on severe exacerbations reported a cost of $€ 1,711$ per severe exacerbation. ${ }^{16}$

The cost of stable disease in Greece had never been thoroughly explored. Very few studies have examined relationships between the costs and severity of the disease in recent years, all of them focusing on the cost of pharmaceutical treatment, while out-of-pocket payments are usually eliminated from many studies. The objective of the present study was to estimate the annual cost of COPD patient during the maintenance phase as well as to explore the relationships between the cost and disease severity and patients' out-ofpocket payments for the management of stable disease.

\section{Methods}

The study sample consisted of 245 COPD patients with stable disease, who visited the outpatient unit of the respiratory clinic of University General Hospital of Larissa, between January 2014 and December 2015. Patients eligible for inclusion were those aged over 40 years and those with diagnosis of COPD according to spirometry test (postbronchodilator forced expiratory volume in 1 second $\left[\mathrm{FEV}_{1}\right] /$ forced vital capacity <0.70). ${ }^{17}$ The study was approved by the University of Thessaly and University Hospital of Larissa Ethic Committees. All subjects gave their informed consent and allowed the use of their personal data for research purposes.

Data were collected retrospectively for a period of 12 months prior to patients' enrollment in the study. Demographic and clinical data were available from patients' medical records and from face-to-face (personal) interviews. Selected patients were classified into four stages of disease severity (based on $\mathrm{FEV}_{1}$ ) and into four groups according to guidelines of the Global Initiative for Chronic Obstructive Lung Disease (GOLD). ${ }^{17}$

Costs were calculated as mean values per patient, in euros (cost base year 2014). Cost estimates were conducted using the Activity Based Costing bottom-up approach, which identifies all resources directly employed for the provision of health care. ${ }^{18}$ Direct medical costs included pharmaceutical treatment of stable disease; medical visits for the management of chronic disease; diagnostic, functional, and imaging tests undergone during maintenance phase; and other chronic treatments such as long-term oxygen therapy
(LTOT) and vaccination (flu or pneumococcal). Direct nonmedical costs included the cost of transportation for patient and patients' attendant. Patient's as well as payer's (social insurance funds) perspectives are taken into consideration. Exacerbation costs (costs for medication, medical tests, medical visits, oxygen therapy during exacerbation and hospitalization cost), and comorbid conditions costs were not included in the study.

Patients' pharmaceutical treatment during maintenance phase was recorded for a period of 12 months before patients' enrollment in the study using brand names. The pharmaceutical cost was calculated based on national pharmaceutical formulary prices. The cost of diagnostic, functional, and imaging tests for stable COPD were calculated based on prices set by the Ministry of Health.

Medical visits during the last 12 months were recorded from personal interview or patients' medical files when available. The mean cost for medical visits was set at $€ 15$ for visits to doctors contracted with social security funds, while visits to units of the national health system (NHS, outpatient units of public hospitals or health centers) were free of charge.

LTOT was calculated based on prices reimbursed by National Organization of Health Care Services Provision, while vaccination was calculated based on the prices set by the National Organization for Medicines.

COPD patients' out-of-pocket payments included direct medical costs such as co-payments for pharmaceutical treatment, diagnostic, functional, and imaging tests, and private payments for medical visits and direct nonmedical costs such as transportation expenses. Patients' co-payments for medication were calculated based on prices set by the Ministry of Health, while co-payments for diagnostic, functional, and imaging tests were calculated as $15 \%$ of the reimbursed prices, when tests were performed in private sector, while tests performed in NHS units had no out-of-pocket payments. Private payments for medical visits were recorded from patients' personal interview. Furthermore, to estimate the cost of transportation, patients were asked about the mode of transport they used to attend medical visits. The cost was calculated based on tickets cost or kilometric allowance.

Descriptive statistics were used to analyze the demographic and clinical characteristics of the study population. Continuous variables were expressed as mean \pm standard deviation, while categorical variables were expressed as percentages. Independent samples $t$-test was also performed, and a cut-off point of $p<0.05$ was used to denote statistical significance. Statistical analysis was performed using 
Statistical Package for the Social Sciences version 20 (IBM Corp, Armonk, NY, USA).

\section{Results}

Our sample consisted of 245 patients, of which 231 (94.3\%) were men (mean age of 69.5 years), $44.9 \%$ were smokers, $52.2 \%$ were ex-smokers, and $2.9 \%$ were non-smokers. At least one comorbidity was present in $83.3 \%$ of the participants. The demographic and clinical characteristics of COPD patients are presented in Table 1.

Table I Demographic and clinical characteristics of COPD patients ( $n=245)$

\begin{tabular}{|c|c|}
\hline Characteristic & Results \\
\hline Age, years (mean [SD]) & $69.5(8.8)$ \\
\hline Gender, male (n [\%]) & $231(94.3)$ \\
\hline BMI, kg/m² (mean [SD]) & $28.9(6)$ \\
\hline Occupational exposure (n [\%]) & $29(11.8)$ \\
\hline \multicolumn{2}{|l|}{ Working status (n [\%]) } \\
\hline Retired & $193(78.8)$ \\
\hline Working & $39(15.9)$ \\
\hline Unemployed & $13(5.3)$ \\
\hline \multicolumn{2}{|l|}{ Smoking habit (n [\%]) } \\
\hline Current smoker & 110 (44.9) \\
\hline Ex-smoker & $128(52.2)$ \\
\hline Nonsmoker & $7(2.9)$ \\
\hline Pack-years (mean [SD]) & $79.6(37.2)$ \\
\hline Years with COPD (mean [SD]) & $6.7(5.6)$ \\
\hline LTOT (n [\%]) & $54(22)$ \\
\hline NIV (n [\%]) & $42(17.1)$ \\
\hline $\mathrm{FEV} \%$ (mean [SD]) & $55.2(19.9)$ \\
\hline \multicolumn{2}{|l|}{ Respiratory symptoms (n [\%]) } \\
\hline Cough & I 44 (58.8) \\
\hline Sputum & $172(70.2)$ \\
\hline Wheezing & $140(57.1)$ \\
\hline Dyspnea & $214(87.3)$ \\
\hline $\mathrm{mMRC} \geq 2$ (n [\%]) & $125(5 \mathrm{I})$ \\
\hline CAT $\geq 10(n[\%])$ & $122(49.8)$ \\
\hline \multicolumn{2}{|l|}{ Frequent comorbidities ( $[\%]$ ) } \\
\hline Hypertension & $121(49.4)$ \\
\hline Coronary heart disease & $47(19.2)$ \\
\hline Chronic heart failure & $26(10.6)$ \\
\hline Diabetes & 47 (19.2) \\
\hline Hyperlipidemia & $48(19.6)$ \\
\hline Prostate diseases & $35(14.3)$ \\
\hline \multicolumn{2}{|l|}{ Stages (GOLD) (n [\%]) } \\
\hline Stage I & $27(\mathrm{II})$ \\
\hline Stage II & $118(48.2)$ \\
\hline Stage III & $71(29)$ \\
\hline Stage IV & $29(11.8)$ \\
\hline \multicolumn{2}{|l|}{ Groups (GOLD) (n [\%]) } \\
\hline$A$ & $57(23.3)$ \\
\hline B & $38(15.5)$ \\
\hline C & $56(22.9)$ \\
\hline $\mathrm{D}$ & $94(38.4)$ \\
\hline
\end{tabular}

Abbreviations: COPD, chronic obstructive pulmonary disease; SD, standard deviation; BMI, body mass index; LTOT, long-term oxygen therapy; NIV, noninvasive ventilation; $\mathrm{FEV}_{1}$, forced expiratory volume in I second; mMRC, modified Medical Research Council dyspnea scale; CAT, COPD Assessment Test; GOLD, Global Initiative for Chronic Obstructive Lung Disease.
The mean number of exacerbations per patient was estimated at 0.91 per year. At least one exacerbation during the previous year was reported in $60.4 \%$ of patients, while $42 \%$ of the reported exacerbations required hospitalization (severe exacerbations). Frequent exacerbations ( $\geq 2$ per year) were seen in $19.6 \%$ of patients.

According to GOLD classification, $40.8 \%$ of COPD patients had already severe or very severe disease based on $\mathrm{FEV}_{1}$ (GOLD stages III-IV), while $61.3 \%$ were categorized in "high-risk" groups (GOLD groups $\mathrm{C}-\mathrm{D})$ ). Classification of patients in GOLD stages and groups are extensively shown in Table 1.

\section{Direct medical costs}

Maintenance medication of patients mainly included longacting muscarinic antagonist (LAMA) + long-acting $\beta 2$ agonist (LABA) + inhaled corticosteroid (ICS) $(40.4 \%$ of patients); LAMA monotherapy ( $24.1 \%$ of patients); LAMA + LABA (10.6\% of patients); and LABA + ICS ( $9.8 \%$ of patients). Other medications (as combination or monotherapy) were reported in lower percentages. The pharmaceutical treatment cost during the maintenance phase was estimated at $€ 731.52$ per patient, which ranged from $€ 310.73$ to $€ 1,220.56$ depending on disease stages (I-IV) and from $€ 444.58$ to $€ 991.23$ depending on GOLD groups (A-D).

For the management of stable COPD, 1,762 medical visits were recorded (28.6\% were follow-up visits and $71.4 \%$ were visits for prescription of medication), providing a mean number of $7.19 \pm 5$ visits per patient. Furthermore, $71.7 \%$ of the visits were to NHS units (outpatient clinics of public hospitals or health centers) and $28.3 \%$ of the visits were to doctors contracted with social security funds. The mean annual per-patient cost was $€ 42.18$, of which $€ 11.69$ was out-of-pocket payments.

Laboratory, functional, and imaging tests included arterial blood gases, spirometry, chest radiography (X-ray and/or computed tomography) and other tests which COPD patients underwent during the maintenance phase. The mean cost for these tests was estimated at $€ 22.40$ per patient per year. Furthermore, the cost of other chronic treatments for COPD was found to be $€ 212.68$, which included LTOT and flu and/or pneumococcal vaccination.

\section{Direct nonmedical costs}

The mean cost of transportation for medical visits was $€ 25.77$ per patient per year. Transportation costs included the cost for patient and patients' caregiver to attend at medical visits for the management of stable COPD. 
Table 2 Annual per-patient costs during maintenance phase $(€)$

\begin{tabular}{|c|c|c|c|c|}
\hline Cost categories & $\begin{array}{l}\text { Total mean } \\
\text { cost per } \\
\text { patient }\end{array}$ & $\begin{array}{l}\text { Percentage } \\
\text { of total } \\
\text { cost }\end{array}$ & $\begin{array}{l}\text { Social } \\
\text { insurance } \\
\text { funds' expenses }\end{array}$ & $\begin{array}{l}\text { Out-of-pocket } \\
\text { payments per } \\
\text { patient }\end{array}$ \\
\hline \multicolumn{5}{|l|}{ Direct medical cost } \\
\hline Pharmaceutical treatment & $731.52(522.36)$ & 70.7 & $547.34(387.96)$ & $184.18(142.58)$ \\
\hline Medical visits & $42.18(72.23)$ & 4.1 & $30.49(56.84)$ & I I.69 (25.85) \\
\hline Laboratory/functional/imaging tests & $22.40(36.21)$ & 2.2 & $21.10(31.76)$ & $1.30(5.30)$ \\
\hline \multicolumn{5}{|l|}{ Other treatments } \\
\hline LTOT & $200.94(407.56)$ & 19.4 & $200.94(407.56)$ & 0 \\
\hline Vaccination & $11.74(21.93)$ & 1.1 & $11.74(21.93)$ & 0 \\
\hline \multicolumn{5}{|l|}{ Direct nonmedical cost } \\
\hline Transportation & $25.77(30.92)$ & 2.5 & 0 & $25.77(30.92)$ \\
\hline Total & $\mathrm{I}, 034.55(835.10)$ & 100 & 811.61 (699.32) & $222.94(\mid 63.31)$ \\
\hline
\end{tabular}

Note: Data are presented as mean $( \pm S D)$.

Abbreviations: LTOT, Long-Term Oxygen Therapy; SD, standard deviation.

\section{COPD patient total annual cost}

The mean annual cost of stable COPD was estimated at $€ 1,034.55$ per patient, out of which $€ 811.61$ were covered by social insurance funds and $€ 222.94$ by patients (out-of-pocket payments). Patient's cost analysis is presented in Table 2.

The mean annual cost for patients with mild to moderate disease (GOLD stages I-II) was $€ 649.93$, while for patients with severe to very severe disease (GOLD stages III-IV) it was $€ 1,592.24(p<0.001)$. The mean annual per-patient cost according to stage of disease severity is depicted in Tables 3 and 4 .

Furthermore, the annual total cost for patients of "highrisk" groups (GOLD groups $\mathrm{C}-\mathrm{D}$ ) was significantly higher compared to the cost for patients of "low-risk" groups (GOLD groups A-B) ( $€ 637.29$ for "low-risk" vs $€ 1,286.14$ for "high-risk," $p<0.001)$. The mean annual cost according to GOLD groups is shown in Tables 5 and 6.

\section{Discussion}

Our study explored the direct costs associated with the management of COPD during the maintenance phase, categorized per social funds' expense and patient's out-of-pocket payments. The mean annual direct cost for each COPD patient was estimated at $€ 1,034.55$, out of which $78.5 \%$ corresponded to social fund expenses and $21.5 \%$ to out-of-pocket payments. The key cost driver of stable disease was chronic inhaled pharmaceutical treatment, which reflected almost $71 \%$ of the total expenditures for the management of stable COPD.

In the international literature, there are significant variations of COPD costs across countries. ${ }^{11,19-24}$ For example, in the study of Foo et $a 1,{ }^{25}$ the annual direct costs of COPD per patient were found to vary widely, from $\$ 504$ (for South Korea) to $\$ 9,981$ (for the United States) (all costs were converted to US dollars [2013]). Another recent study from Italy showed that the direct cost of COPD was $€ 2,932.20$, of which $€ 498.6$ referred to pharmaceutical costs, $€ 463.20$ to outpatient costs, and $€ 1,970.40$ to hospitalization costs. ${ }^{26}$ However, these results are not easily comparable with our study, because of geographic differences and because of different measurement methods across studies.

In Greece, the only study to have made an estimate of the total cost of COPD is the one of Souliotis et al, ${ }^{15}$ which reports

Table 3 Mean annual per-patient cost of COPD during maintenance phase according to GOLD stages based on FEV, ( $€$ )

\begin{tabular}{|c|c|c|c|c|}
\hline Cost categories & Stage I & Stage II & Stage III & Stage IV \\
\hline \multicolumn{5}{|l|}{ Direct medical cost } \\
\hline Pharmaceutical treatment & $310.73(349.27)$ & $560.02(440.06)$ & $976.81(437.16)$ & $\mathrm{I}, 220.56(53 \mathrm{I} .6 \mathrm{I})$ \\
\hline Medical visits & $35.93(61.66)$ & 35.51 (69.49) & 54.51 (77.93) & $45.00(77.54)$ \\
\hline Laboratory/functional/imaging tests & $7.94(6.32)$ & 19.31 (37.39) & $29.22(41.20)$ & $31.75(29.22)$ \\
\hline \multicolumn{5}{|l|}{ Other treatments } \\
\hline LTOT & $40.00(207.85)$ & $54.91(222.65)$ & $308.03(466.58)$ & $682.76(521.20)$ \\
\hline Vaccination & $3.40(3.10)$ & $12.90(23.79)$ & $10.24(19.48)$ & $18.42(27.25)$ \\
\hline \multicolumn{5}{|l|}{ Direct nonmedical cost } \\
\hline Transportation & $10.23(15.57)$ & $22.58(29.43)$ & $29.78(3 \mathrm{I} .5 \mathrm{I})$ & $43.40(36.96)$ \\
\hline Total & $408.23(503.19)$ & 705.23 (596.79) & I,408.59 (742.00) & $2,041.89(858.19)$ \\
\hline
\end{tabular}

Note: Data are presented as mean (SD).

Abbreviations: COPD, chronic obstructive pulmonary disease; GOLD, Global Initiative for Chronic Obstructive Lung Disease; FEV LTOT, long-term oxygen therapy; SD, standard deviation. 
Table 4 Mean annual expenses for social insurance funds and out-of-pocket payments per patient according to disease stages (I-IV) (€)

\begin{tabular}{|c|c|c|c|}
\hline $\begin{array}{l}\text { GOLD } \\
\text { stage }\end{array}$ & $\begin{array}{l}\text { Total mean cost } \\
\text { per patient }\end{array}$ & $\begin{array}{l}\text { Social insurance } \\
\text { funds' expenses }\end{array}$ & $\begin{array}{l}\text { Out-of-pocket } \\
\text { payments per } \\
\text { patient }\end{array}$ \\
\hline & & & 94.7 \\
\hline Stage II & 705.23 (596.79) & $532.93(482.02)$ & $172.30(13$ \\
\hline tage III & I,408.59 (742.00) & I,II8.02 (649 & $290.57(143.44)$ \\
\hline tage IV & $2,041.89(858.19)$ & I,659.II (730.56) & $382.78(174.86)$ \\
\hline
\end{tabular}

Note: Data are presented as mean (SD).

Abbreviation: SD, standard deviation.

that the total cost of COPD in Greece is $€ 4,729.9$, of which $€ 2,809.70$ was for direct medical costs ( $€ 835$ for maintenance phase costs and $€ 462.30$ for additional resources cost [such as LTOT] while $€ 1,512.40$ was for exacerbations costs). However, due to the fact that in this study a different methodology was used (the study was based on expert opinion rather than patient-level data) and different parameters were taken into consideration, it is difficult to compare with the current study. A similar methodology as in our study (bottom-up approach) was used in the study of Geitona et $\mathrm{al} ;{ }^{16}$ however, their estimates referred only to the cost of severe exacerbations ( $€ 1,711$ per severe exacerbation).

Other studies from Greece had studied only the cost of inhaled medication in COPD patients, with the most recent study reporting that the mean annual cost of COPD maintenance treatment per patient was €952.92.27 Similar results were reported in the study of Tzovaras et al, ${ }^{28}$ with the annual per-patient cost for COPD medication estimated at $€ 897$. Those studies concluded that there were slightly higher costs for maintenance medication compared with the present study, in which the pharmaceutical cost was estimated at $€ 731.52$ per patient per year. These differences in the pharmaceutical cost could be due to the fact that in this study the percentage of patients in early stages of the disease (who might not received medication on a regular basis, but treatment only on-demand) was higher than in the abovementioned studies.

In the present study, the total direct maintenance cost was increased with disease progression according to GOLD classification in stages (I-IV) and groups (A-D). More specifically, regarding the cost according to disease severity, the mean annual per-patient cost was two to three times higher for those with advanced disease (stages III-IV) compared to those with mild to moderate disease (stages I-II). Similarly, the cost was doubled for patients in "high-risk" groups (groups C-D) compared to the "low-risk" patients (groups A-B). Similar results were also reported in our previous study, which only looked at the pharmaceutical cost of the disease, ${ }^{27}$ and in the study of Boland et al, ${ }^{29}$ which showed that GOLD stages and groups were strongly related with the total health care costs of COPD. Moreover, a study from Sweden supported that the costs of COPD were highly dependent on disease severity, with the mean total costs for a subject with very severe disease being 29 times higher than for a subject with mild COPD. ${ }^{11}$

The pharmaceutical cost of stable disease proved proportional to the severity of COPD, varying from $€ 310.73$ to $€ 1,220.56$ depending on disease stages (I-IV) and from $€ 444.58$ to $€ 991.23$ depending on GOLD groups (A-D). This increase of medication cost was also evident in the study of Tzovaras et al ${ }^{28}$ where the annual per-patient cost for COPD medication started from $€ 413$ in patients with mild disease (stage I), rising to $€ 892$ and $€ 1,948$ in patients with stage III and stage IV disease, respectively. However, the study referred to prices before economic crisis, which differ from the present, thus being noncomparable with our findings. Furthermore, previous data recently published from our group showed that the annual treatment cost for stable disease ranged from $€ 614.44$ to $€ 1,302.03$ depending on disease stages (I-IV) and from $€ 715$ to $€ 1,101.05$ depending on GOLD groups (A-D). ${ }^{27}$ These differences may be present

Table 5 Mean annual per-patient cost of COPD during maintenance phase according to GOLD groups $(€)$

\begin{tabular}{lllll}
\hline Cost categories & Group A & Group B & Group C & Group D \\
\hline Direct medical cost & & & & \\
$\quad$ Pharmaceutical treatment & $444.58(410.77)$ & $551.25(406.61)$ & $709.95(534.45)$ & $991.23(497.39)$ \\
$\quad$ Medical visits & $39.73(74.03)$ & $26.58(53.55)$ & $43.66(75.25)$ & $49.10(75.80)$ \\
$\quad$ Laboratory/functional/imaging tests & $14.52(25.63)$ & $25.53(50.14)$ & $20.46(33.52)$ & $27.07(36.24)$ \\
$\quad \begin{array}{llll}\text { Other treatments } \\
\quad \text { LTOT }\end{array} \quad 18.95(143.05)$ & $125.53(339.69)$ & $159.11(380.29)$ & $366.70(490.51)$ \\
$\quad$ Vaccination & $14.22(24.75)$ & $12.36(22.71)$ & $6.73(15.64)$ & $12.96(22.85)$ \\
$\begin{array}{l}\text { Direct nonmedical cost } \\
\quad \text { Transportation }\end{array}$ & $18.01(24.78)$ & $26.95(35.03)$ & $20.83(24.56)$ & $32.94(34.49)$ \\
Total & $550.01(535.59)$ & $768.20(644.63)$ & $960.74(818.29)$ & $1,480.00(847.91)$ \\
\hline
\end{tabular}

Note: Data are presented as mean (SD).

Abbreviations: GOLD, Global Initiative for Chronic Obstructive Lung Disease; LTOT, long-term oxygen therapy; SD, standard deviation. 
Table 6 Mean annual expenses for social insurance funds and out-of-pocket payments per patient according to GOLD groups (A-D) (€)

\begin{tabular}{llll}
\hline $\begin{array}{l}\text { GOLD } \\
\text { groups }\end{array}$ & $\begin{array}{l}\text { Total mean } \\
\text { cost per } \\
\text { patient }\end{array}$ & $\begin{array}{l}\text { Social } \\
\text { insurance } \\
\text { funds' expenses }\end{array}$ & $\begin{array}{l}\text { Out-of-pocket } \\
\text { payments per } \\
\text { patient }\end{array}$ \\
\hline Group A & $550.01(535.59)$ & $412.55(414.35)$ & $137.46(124.82)$ \\
Group B & $768.20(644.63)$ & $593.64(560.72)$ & $174.56(131.00)$ \\
Group C & $960.74(818.29)$ & $751.67(678.60)$ & $209.07(158.99)$ \\
Group D & I,480.00(847.9I) & I,I77.40 (726.54) & $302.60(163.85)$ \\
\hline
\end{tabular}

Note: Data are presented as mean (SD).

Abbreviations: GOLD, Global Initiative for Chronic Obstructive Lung Disease; $\mathrm{SD}$, standard deviation.

in the early stages of the disease, probably due to the fact that patients with mild disease (the percentage of which was higher in the current study) might not receive medication on daily basis but only on demand.

In our study, $61.3 \%$ of the subjects who participated were classified to the "high-risk" groups (GOLD groups C-D). Similar results were reported in a previous study of our group, in which more than $60 \%$ of COPD patients were allocated to high-risk groups. ${ }^{30}$ This large percentage of "high-risk" patients might be responsible for the significantly high percentage of patients $(40.4 \%)$ receiving a triple combination therapy (LAMA + LABA + ICS) as maintenance medication. The study of Papala et $\mathrm{al}^{31}$ also confirmed that a large proportion of patients use triple combination therapy at all stages of the disease.

For the management of stable disease, $7.2 \pm 5$ medical visits were recorded per patient per year. This number seems to be extremely high as it does not include visits due to COPD exacerbations. However, most of these visits (71.4\%) were for the prescription of inhaled COPD medication, due to the fact that medication in Greece is prescribed on a monthly or a 3-month basis, increasing the visits to GPs or specialists only for prescription of medication. Many medical visits were also reported in the study of Foo et $a 1,{ }^{25}$ with the mean number of contacts with GPs ranging from 2.6 to 8.3 and the contacts with specialists ranging from 1.6 to 5.1 visits depending on different countries studied; however, these might include visits for exacerbations too. Furthermore, in the present study, $71.7 \%$ of the visits were at the NHS. In Greece, visits to these units are free of charge, and so it is obvious why most of the patients prefer to seek for medical assistance in public health facilities, as the economic downturn has significant consequences for patients with chronic diseases. ${ }^{27}$

The presence of comorbidities was evident in our sample, as $\sim 84 \%$ of COPD patients reported at least one concomitant disease, with the most common comorbid condition being hypertension (49.4\%), followed by hyperlipidemia, diabetes, coronary heart disease, and chronic heart failure. Our results agree with those reported in the GOLDEN study, which demonstrated a $82 \%$ presence of comorbid diseases, with hypertension, diabetes, and heart failure being the most frequent diseases mentioned $(55.3 \%, 20.6 \%$, and $19.4 \%$, respectively). ${ }^{8,32}$ Mitonas et $\mathrm{al}^{33}$ also reported arterial hypertension and coronary heart disease as the most frequent diseases in COPD patients. Comorbidities in patients with COPD impose a substantial economic burden as studies from many countries have shown that the cost of COPD is higher among those with comorbid conditions compared to those free of other diseases. ${ }^{34,35}$

Our study has several limitations. In particular, it was designed to estimate the direct cost of COPD during the maintenance phase and not to evaluate the cost of exacerbations, which contributes to a significant proportion of the total cost in many studies, ${ }^{11,15,25-26}$ as well as the indirect cost of the disease. Due to the absence of related data, these costs could not be estimated. Another important limitation was that the large proportion of patients visited the NHS units which is free of charge, consequently leading to an underestimation of the cost of medical visits. A final limitation might be the small size of our population. However, our results can be generalized to the Greek population since University General Hospital of Larissa belongs to NHS hospitals and uses the official prices of all NHS hospitals. It should be noted that further research is needed on this topic in order for our results to be comparative and representative and to be able to conclude with more reliable estimates. Despite these weaknesses, a strength that should be noted is that our study showed that social insurance funds are the key payers for treating COPD patients.

\section{Conclusion}

The results of the present study demonstrate that the management of stable COPD in Greece is associated with significant economic burden, with pharmaceutical treatment found to be the key cost driver and social insurance funds the key payer for treating COPD patients. The cost of stable disease is shown to be proportional to the severity of COPD, and this is doubled in patients of "high-risk groups."

\section{Disclosure}

The authors report no conflicts of interest in this work.

\section{References}

1. World Health Organization. Chronic respiratory diseases. Chronic obstructive pulmonary disease (COPD) - Burden of COPD. Available from: http://www.who.int/respiratory/copd/burden/en/index.html. Accessed July 10, 2017. 
2. Lozano R, Naghavi M, Foreman K, et al. Global and regional mortality from 235 causes of death for 20 age groups in 1990 and 2010: a systematic analysis for the Global Burden of Disease Study 2010. Lancet. 2012;380:2095-2128.

3. Murray CJL, Vos T, Lozano R, et al. Disability-adjusted life years (DALYs) for 291 diseases and injuries in 21 regions, 1990-2010: a systematic analysis for the Global Burden of Disease Study 2010. Lancet. 2012;380:2197-2223.

4. Minas M, Hatzoglou C, Karetsi E, et al. COPD prevalence and the differences between newly and previously diagnosed COPD patients in a spirometry program. Prim Care Respir J. 2010;19(4):363-370.

5. Minas M, Koukosias N, Zintzaras E, Kostikas K, Gourgoulianis KI. Prevalence of chronic diseases and morbidity in primary health care in central Greece: an epidemiological study. BMC Health Serv Res. 2010;10:252.

6. Tzanakis N, Anagnostopoulou U, Filaditaki V, Christaki P, Siafakas N. Prevalence of COPD in Greece. Chest. 2004;125(3):892-900.

7. Kotrogianni F, Malli F, Gourgoulianis KI. Underdiagnosis of respiratory diseases during an economic downturn and the need for spirometry as a screening test. J Bras Pneumol. 2013;39(2):254-255.

8. Alexopoulos EC, Malli F, Mitsiki E, Bania EG, Varounis C, Gourgoulianis KI. Frequency and risk factors of COPD exacerbations and hospitalizations: a nationwide study in Greece (Greek Obstructive Lung Disease Epidemiology and health ecoNomics: GOLDEN study). Int J Chron Obstruct Pulmon Dis. 2015;10:2665-2674.

9. Spyratos D, Chloros D, Michalopoulou D, Sichletidis L. Estimating the extent and economic impact of under and overdiagnosis of chronic obstructive pulmonary disease in primary care. Chron Respir Dis. 2016; 13(3):240-246.

10. Minas M, Verrou-Katsarou I, Mystridou P, Apostolidou E, Hatzoglou C, Gourgoulianis KI. Two-year mortality of patients with COPD in primary health care: an observational study. Int J Gen Med. 2012;5: 815-822.

11. Jansson SA, Backman H, Stenling A, Lindberg A, Rönmark E, Lundbäck B. Health economic costs of COPD in Sweden by disease severity - has it changed during a ten years period? Respir Med. 2013; 107(12):1931-1938.

12. Ramsey SD, Sullivan SD. The burden of illness and economic evaluation for COPD. Eur Respir J Suppl. 2003;41:29s-35s.

13. Guarascio AJ, Ray SM, Finch CK, Self TH. The clinical and economic burden of chronic obstructive pulmonary disease in the USA. Clinicoecon Outcomes Res. 2013;5:235-245.

14. European Lung White Book. The economic burden of lung disease. Available from: http://www.erswhitebook.org/chapters/the-economicburden-of-lung-disease/. Accessed July 10, 2017.

15. Souliotis K, Kousoulakou H, Hillas G, Tzanakis N, Toumbis M, Vassilakopoulos T. The direct and indirect costs of managing chronic obstructive pulmonary disease in Greece. Int J Chron Obstruct Pulmon Dis. 2017;12:1395-1400.

16. Geitona M, Hatzikou M, Steiropoulos P, Alexopoulos EC, Bouros D. The cost of COPD exacerbations: a university hospital-based study in Greece. Resp Med. 2011;105:402-409.

17. The Global Initiative for Chronic Obstructive Lung Disease (GOLD). Global strategy for the diagnosis, management and prevention of chronic obstructive pulmonary disease (Updated 2016). Available from: http:// www.goldcopd.org/. Accessed July 10, 2017.
18. Wordsworth S, Ludbrook A, Caskey F, et al. Collecting unit cost data in multicentre studies creating comparable methods. Eur J Health Econ. $2005 ; 6: 38-44$

19. Dal Negro RW, Tognella S, Tosatto R, Dionisi M, Turco P, Donner CF. Costs of chronic obstructive pulmonary disease (COPD) in Italy: the SIRIO study (social impact of respiratory integrated outcomes). Respir Med. 2008;102(1):92-101. Epub 2007 Sep 19.

20. Punekar YS, Shukla A, Müllerova H. COPD management costs according to the frequency of COPD exacerbations in UK primary care. Int J Chron Obstruct Pulmon Dis. 2014;9:65-73.

21. Kamusheva M, Dimitrova M, van Boven JF, et al. Clinical characteristics, treatment patterns, and socio-economic burden of COPD in Bulgaria. J Med Econ. 2017;20(5):503-509.

22. Wacker ME, Jörres RA, Schulz H, et al; COSYCONET-Consortium. Direct and indirect costs of COPD and its comorbidities: results from the German COSYCONET study. Respir Med. 2016;111:39-46.

23. Khakban A, Sin DD, FitzGerald JM, et al. Ten-year trends in direct costs of COPD: a population-based study. Chest. 2015;148(3):640-646.

24. De Miguel-Díez J, Carrasco-Garrido P, Rejas-Gutierrez J, et al. The influence of heart disease on characteristics, quality of life, use of health resources, and costs of COPD in primary care settings. BMC Cardiovasc Disord. 2010;10:8

25. Foo J, Landis SH, Maskell $\mathrm{J}$, et al. Continuing to confront COPD international patient survey: economic impact of COPD in 12 countries. PLoS One. 2016;11(4):e0152618.

26. Dal Negro RW, Bonadiman L, Turco P, Tognella S, Iannazzo S. Costs of illness analysis in Italian patients with chronic obstructive pulmonary disease (COPD): an update. Clinicoecon Outcomes Res. 2015;7: 153-159.

27. Stafyla E, Kerenidi T, Gerogianni I, Geitona M, DaniilZ, Gourgoulianis KI. The pharmacological cost of COPD during Greek economic crisis. Int J Chron Obstruct Pulmon Dis. 2017;12:461-466.

28. Tzovaras NZ, Kouloumenta VN, Gourgoulianis KI. The economic impact of late detection of COPD in general practice. Chest. 2005 127(1):412-413.

29. Boland MR, Tsiachristas A, Kruis AL, Chavannes NH, Rutten-van Mölken MP. Are GOLD ABCD groups better associated with health status and costs than GOLD 1234 grades? A cross-sectional study. Prim Care Respir J. 2014;23(1):30-37.

30. Stafyla E, Kerenidi T, Gourgoulianis KI. Chronic obstructive pulmonary disease exacerbation frequency and severity. Int J Chron Obstruct Pulmon Dis. 2013;8:533-535.

31. Papala M, Kerenidi N, Gourgoulianis KI. Everyday clinical practice and its relationship to 2010 and 2011 GOLD guideline recommendations for the management of COPD. Prim Care Respir J. 2013;22(3): 362-364.

32. Mitsiki E, Bania E, Varounis C, Gourgoulianis KI, Alexopoulos EC Characteristics of prevalent and new COPD cases in Greece: the GOLDEN study. Int J Chron Obst Pulmon Dis. 2015;10:1371-1382.

33. Mitonas G, Juvana A, Daniil Z, Hatzoglou C, Gourgoulianis K. COPD patients' medical care and support in Greece during financial crisis. Int J General Med. 2016;9:401-407.

34. Mannino DM, Higuchi K, Yu TC, et al. Economic burden of COPD in the presence of comorbidities. Chest. 2015;148(1):138-150.

35. Wouters EF. Economic analysis of the confronting COPD survey: an overview of results. Respir Med. 2003;97(Suppl C):S3-S14.
International Journal of COPD

\section{Publish your work in this journal}

The International Journal of COPD is an international, peer-reviewed journal of therapeutics and pharmacology focusing on concise rapid reporting of clinical studies and reviews in COPD. Special focus is given to the pathophysiological processes underlying the disease, intervention programs, patient focused education, and self management protocols.

\section{Dovepress}

This journal is indexed on PubMed Central, MedLine and CAS. The manuscript management system is completely online and includes a very quick and fair peer-review system, which is all easy to use. Visit http://www.dovepress.com/testimonials.php to read real quotes from published authors. 